\title{
A Pick and Place Robot: A Flexible Robot with Adjustable Rubber Hand
}

\author{
Ashlesha D. Kulkarni \\ Student ME VLSI \& Embedded \\ System,Shree Ramchandra \\ college of engineering \\ Lonikand (Pune), India
}

\author{
K. Sujatha \\ HOD Of E\&TC Department \\ Shri Ramchandra College Of \\ Engineering Lonikand Pune
}

\author{
N.A. Shinde \\ Lecturer at E\&TC Department \\ SIT Polytechnic \\ yadrav,Ichalkaranji
}

\begin{abstract}
In this paper, we are going to proposed design of an intelligent robot having adjustable rubber hand to perform pick and place task. The proposed robot can pick any random shape of object with its flexible rubber hand this flexible hand is self adjusted according to the shape of the object. For that purpose we provide the pressure switches on the robots hand to judge the pressure required to pick the particular object. The proposed robot is wireless and for proper wireless communication we used zig bee. We can control all the movements of robot such that left movement, right movement, forward and backward movement, up down movement, pick the object and place that object at required place with the help of personal computer. We can successfully control the force and pressure required for picking the object through pressure switches. Due to use of adjustable rubber hand with spunj the friction between the object and hand of the robot is increased with great extent so we can achieve successful grip.
\end{abstract}

We performed many experiments on the objects like bottle, ball, soft toys, talcum powder container, conical objects, oil container and many more similar objects. These sets of experiments were performed with an average success rate of 95\% in pick-and-place tasks In short in this paper we will proposed how the embedded system is created for making a small mechatronics system used for pick and place task. In future we implement this type of system in nuclear industries where hazardous nuclear rays can affect the human health severely .So we can replace the human workers by such system.[1][5]

\section{Keywords}

flexibility, pick and place, flexible rubber hand, Intelegent robot,pressure switches

\section{INTRODUCTION}

Before going towords main topic first we see what is robotics?Robotics is a branch of electronics, mechanical and computer science that deals with design, construction and operation of robot which is used for automation purpose. Here computer science is used for controlling, sencing and handling purpose.In this paper we are going to proposed design of an intelligent robot having adjustable rubber hand to perform pick and place task.This robot can be used for grasping any type of objects having various shapes.Figure 1.1 shows the complete block diagram of this system.

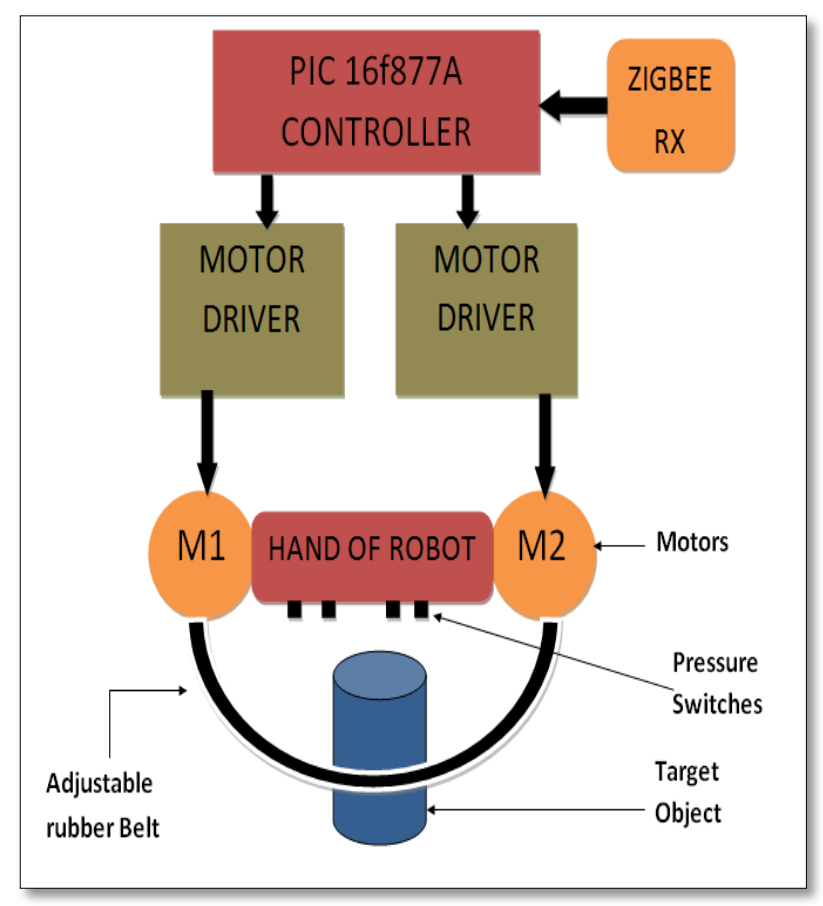

Fig 1.1: Block Diagram of Inteligent robot with flexible rubber hand

In this system we are going to build embedded system by using PIC microcontroller 187. Here PIC microcontroller acts as a central processing unit(CPU).The input to this controller is given from personal computer via zigbee transreceiver. We can control following movements of robot through the PC

1.Movements of Robot

- Forward movement

- $\quad$ Backward movenment

- $\quad$ Left movement

- $\quad$ Right movement

2.Movements of Robotic Hand

- Up movement

- Down movement

- $\quad$ Picking the object

- $\quad$ Placing the object

This robot can be used for picking any random shape of object with its flexible rubber hand this flexible hand is self adjusted according to the shape of the object. For that purpose we provide the pressure switches on the robots hand to judge the 
pressure required to pick the particular object. The proposed robot is wireless and for proper wireless communication we used zig bee. We can control all the movements of robot such that left movement, right movement, forward and backward movement, up down movement, pick the object and place that object at required place with the help of personal computer. We can successfully control the force and pressure required for picking the object through pressure switches. Due to use of adjustable rubber hand with spunj the friction between the object and hand of the robot is increased with great extent so we can achieve successful grip.[2]

Basically this type of robot is used for pick and place task.This type of robot have following two properties.

\section{Self adaptivity \\ 2.Self flexibility}

Self adaptivity means it will do many things automatically like sensing the pressure required to pick the particular object, control on rotation movement of motor etc. and self flexibility means it can pick any shape of the object i.e. its rubber hand is self adjusted according to the shape of the object.This two properties help the robot to increase the success rate for pick $\&$ place task

Basically this robot is flexible thus it can pick any type of object. This is because of with the help of rubber belt we can achive the stable grip. Due to use of rubber belt friction between object and rubber hand is increased in great extent such that success rate of pick and place is increased.

Before going towords main concept first we see what is Robotics?

\section{WHAT IS ROBOTICS?}

Robotics is a branch of Electronics, Mechanical, Computer science whih deals with construction, operation, and applications of robot in all system where automation is required.Basically this technology deals wth replacement of human with the machine to do any kind of work.It is basically used in harsh environment where ordinary human can not reach.In our system robots are used along with pressure switch mechanism Pressure switch calculates pressure requires to pick the object and according to ths control is given to the motors.[3]

\section{HARDWARE REQUREMENTS}

\subsection{PIC 16f877a:}

PIC16F877A devices is available in 40-pin and 44-pin packages. PIC microcontrollers ( Programmable Interface Controllers), are electronic circuits that can be programmed to carry out a vast range of tasks. They can be programmed with the help of timers .[2]

\subsection{Motor Driver}

Motor driver is used to control the operation of motors. Rotations of DC motors are controlled with the help of motor driver L298N Circuit.

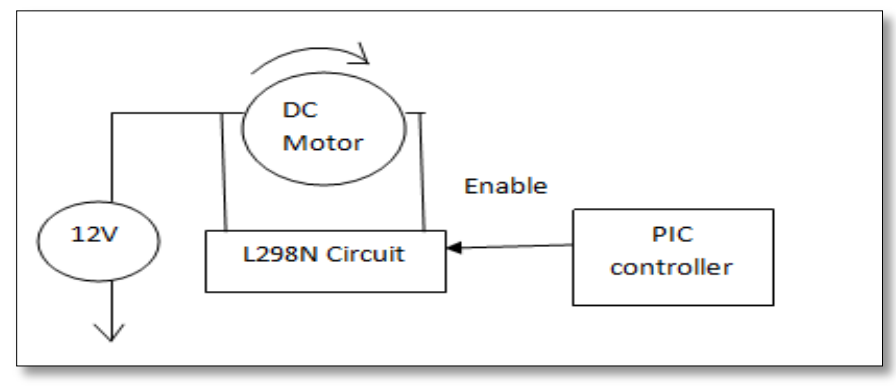

Fig: L298N motor driver.

\subsection{Motors}

Near about 4 DC motors are used for motion of the robot. And

2 DC motor are used to adjust the shape of the rubber hand.

According to the instruction given through the PC two motors are rotated. Due to this shape of the belt is automatically adjusted according to the shape of object.[3]

\subsection{Aluminum Plate Coated with sponge:}

Aluminum plate is used to construct the hand of the robot Which just acts as a palm of the hand. This plate is covered with sponge. This sponge increase the friction between hand of the robot and object. On this aluminum plate pressure switches are connected.[3]

\subsection{Pressure Switches}

Four pressure switches are mounted on aluminum plate. According to instruction given through the PC and according to shape of the object motors are rotated and shape of the rubber hand is adjusted. When the rubber hand tightly grab the object then it will apply the pressure on the pressure switches. Due to the applied pressure switch position will changes and rotations of DC motors automatically get stopped.[4]

\subsection{Rubber Hand}

Generally rubber hand is made up of Polysiloxane carbon material. This rubber hand is flexible which can self adjusted according to the shape of the object Rubber belt is fitted on the dc motors. When we give the command through PC then dc motors start rotating and belt starts adjusting its shape according to the shape of the object. When belt get fully adjusted then pressure switches senses it and they stop the rotations of motor.[4]

\section{GRASPING PROCEDURE}

Grasping process that is pick and place process is done in following three steps.

\section{Planning step \\ 2. Grasping step \\ 3. Releasing step}

In planning steps all the planning about pick and place process is completed e.g. which object we want to pick? How many weight of that object? Where we want to place that object?

All other calculations are completed in this phase. After completing this actual grasping process is completed and then object is placed at certain place.[1] 


\section{EXPERIMENMTS \& RESULTS}

Some trials are taken on different objects and finally it is conclude that overall success rate of pick \& place is near about $95 \%$ Table below shows different trials are taken on different objects and percentage of success rate of each pick and place

Table 5.1: Results Showing Success Rate in Pick and place task.

\begin{tabular}{|c|c|c|c|c|c|c|c|}
\hline \multirow[t]{2}{*}{ No } & \multirow[t]{2}{*}{ Object } & \multicolumn{5}{|c|}{ Trial } & \multirow{2}{*}{$\begin{array}{l}\text { Success } \\
\text { Percentag } \\
\text { e }\end{array}$} \\
\hline & & $\mathbf{A}$ & B & $\mathbf{C}$ & D & $\mathbf{E}$ & \\
\hline 1 & Oil bottle & 20 & 20 & 20 & 20 & 20 & $100 \%$ \\
\hline 2 & Lotion & 20 & 15 & 20 & 20 & 20 & $95 \%$ \\
\hline 3 & Paper roll & 20 & 20 & 20 & 20 & 20 & $100 \%$ \\
\hline 4 & Soft toy & 20 & 20 & 20 & 15 & 20 & $95 \%$ \\
\hline 5 & $\begin{array}{l}\text { Conical } \\
\text { object }\end{array}$ & 20 & 10 & 20 & 15 & 15 & $80 \%$ \\
\hline 6 & $\begin{array}{l}\text { Talcum } \\
\text { powder }\end{array}$ & 20 & 20 & 20 & 20 & 20 & $100 \%$ \\
\hline 7 & $\begin{array}{l}\text { Cotton } \\
\text { doll }\end{array}$ & 20 & 20 & 20 & 20 & 15 & $95 \%$ \\
\hline 8 & $\begin{array}{l}\text { Rubber } \\
\text { ball }\end{array}$ & 20 & 20 & 17 & 20 & 18 & $95 \%$ \\
\hline $\begin{array}{l}\text { Ov } \\
95\end{array}$ & I success & & & & & & \\
\hline
\end{tabular}

Figure below shows graph of success rate for different trials taken on different object

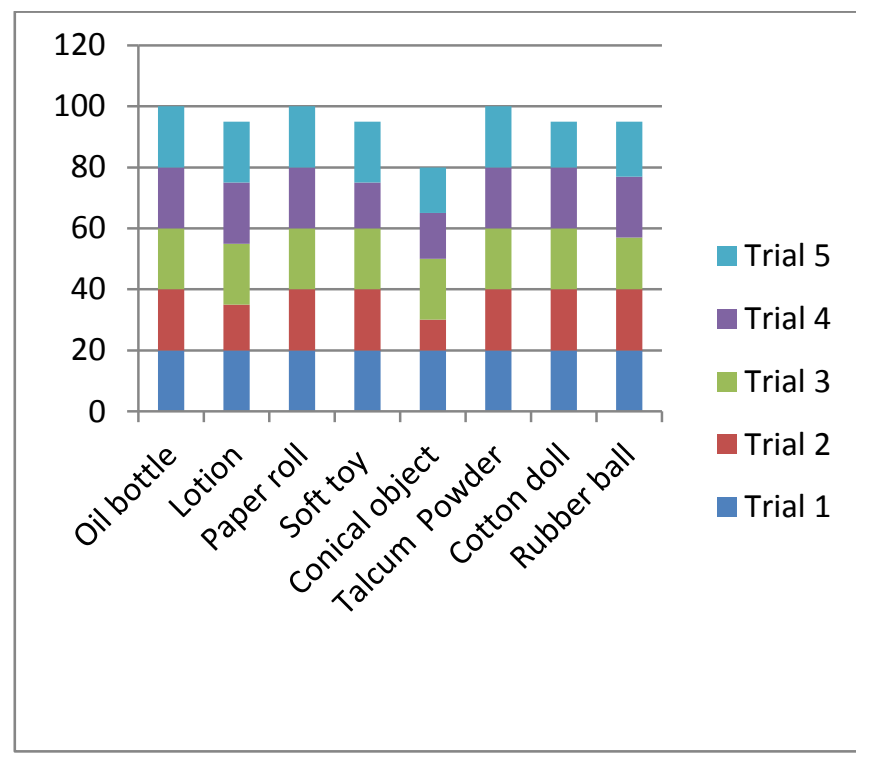

Fig.5.2:Graph showing success rate of different trials
Picture below shows actual Photograph Of practical setup:

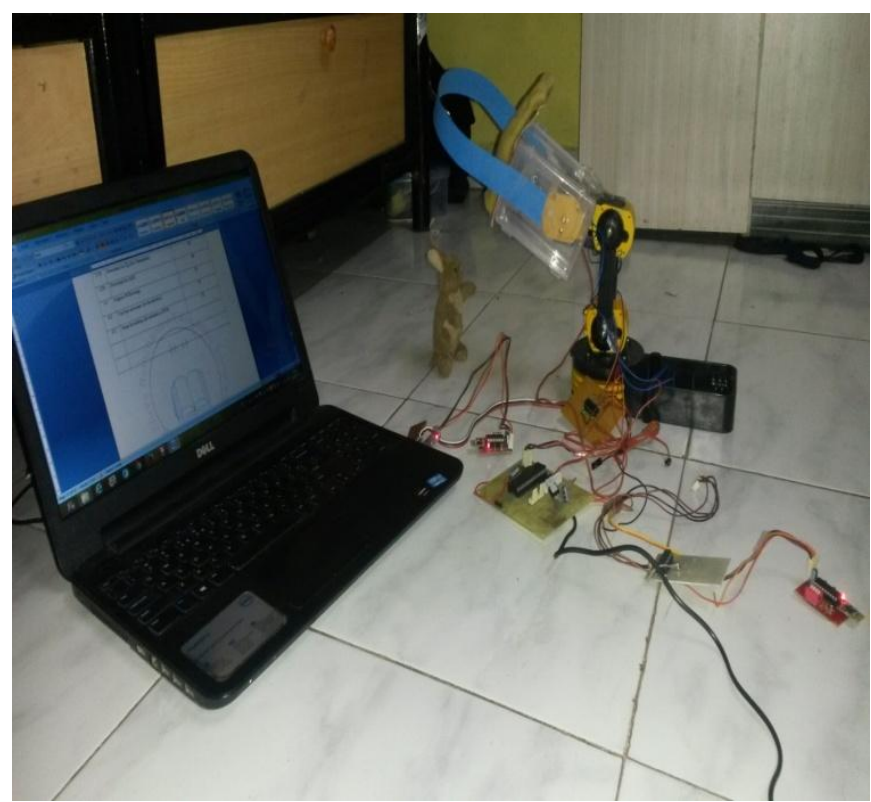

Picture below shows Robot Picking an Object With its Rubber Hand

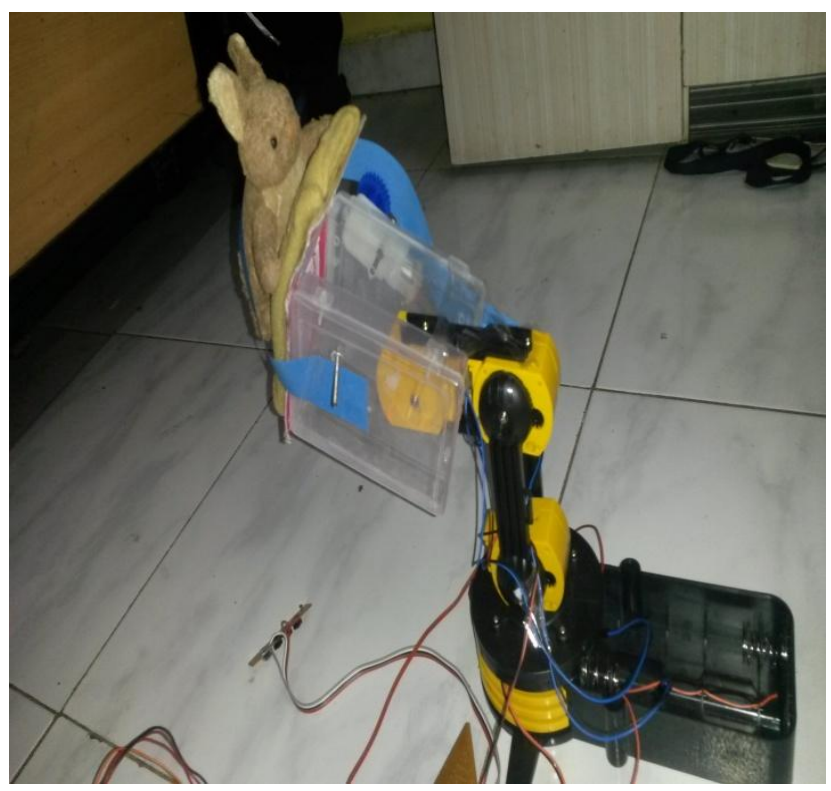

\section{CONCLUSION}

From all above discussion, we have addressed the issues that prevent current robotic hands from being commercialized and have considered the various approaches taken by many researchers to overcome these difficulties. As an intermediate solution focused on practical application such as with current technology, a simple enveloping robot has been proposed for pick-and-place task. This robot stably grips various real-life objects with an average of success rates of $95 \%$ due to its advantageous features of self-adaptivity and flexibility

\section{REFERENCES}

[1] S. L. Yuen, J. F. Jin, and N. L. Doh, "A system framework for evalu- ating minimal robot in cartesian grasping system," in Proc. Int. Conf. Electron., Inf., Commun., 2010, pp. 222-225. 
[2] Y. H. Lee, J. F. Jin, C. Nam, J. Kim, and N. L. Doh, "Development of minimal robot: Preliminary result of a simple and flexible envelop- ing robot," in Proc. IEEE/RSJ Int. Conf. Intell. Robots Syst., 2009, pp. 1779-1784.

[3] L. Birglen, T. Laliberté, and C. Gosselin, "Grasping vs manipulating,"Adv. Robot., vol. 40, pp. 7-31, 2008.

[4] W. Gruver, "Intelligent robotics in manufacturing, service, and rehabilita- tion: An overview," IEEE Trans. Ind. Electron., vol. 41, no. 1, pp. 4-11, Feb. 2008.

[5] J. Salisbury and J. Craig, "Articulated hands: Force control and kinematic issues," Int. J. Robot. Res., vol. 1, no. 1 , pp. 4-17, 2008.

[6] S. Jacobsen, E. Iversen, R. Johnson, and K. Biggers, "Design of the Utah/MIT dextrous hand," in Proc. IEEE Int. Conf. Robot. Autom., 2007, pp. 1520-1532.

[7] Barrett Hand. [Online]. Available: http://barrett.com/robot/index.htm

[8] F. Lotti, P. Tiezzi, G. Vassura, L. Biagiotti, G. Palli, and C. Melchiorri, "Development of UB hand 3: Early results," in Proc. IEEE Int. Conf. Robot. Autom., 2005, pp. 4488-4493.

[9] J. Butterfass, M. Grebenstein, H. Liu, and G. Hirzinger, "DLR-hand II: Next generation of a dextrous robot hand," in Proc. IEEE Int. Conf. Robot. Autom., 2005, pp. 109114.

[10] H. Kawasaki, T. Komatsu, and K. Uchiyama, "Dexterous anthropomor- phic robot hand with distributed tactile sensor: Gifu hand II," IEEE/ASME Trans. Mechatron., vol. 7, no. 3, pp. 296-303, Sep. 2005.

A. M. Dollar and R. D. Howe, "Simple, robust autonomous grasping in unstructured environments," in Proc. IEEE Int. Conf. Robot. Autom.,2004, pp. 4693-47

[11] R. O. Ambrose, H. Aldridge, R. S. Askew, R. R. Burridge, W. Bluethmann, M. Diftler, C. Lovchik, D. Magruder, and F. Rehnmark, "Robonaut: NASA's space humanoid," IEEE Intell. Syst. Appl., vol. 15, no. 4, pp. 57-63, Jul./Aug. 2004.

[12] M. C. Carrozza, C. Suppo, F. Sebastiani, B. Massa, F. Vecchi, R. Lazzarini, M. R. Cutkosky, and P. Dario, "The spring hand: Develop- ment of a selfadaptive prosthesis for restoring natural grasping," Auton. Robots, vol. 16, no. 2, pp. 125-141, Mar. 2004

[13] S. Hirose and Y. Umetani, "Soft gripper," in Proc. Int. Symp. Exp. Robot., 2003, pp. 112.

[14] B. Massa, S. Roccella, M. C. Carrozza, and P. Dario, "Design and de- velopment of an underactuated prosthetic hand," in Proc. IEEE Int. Conf. Robot. Autom., 2003, pp. 3374-3379. 